\title{
Genomic prediction of dry matter intake in dairy cattle from an international data set consisting of research herds in Europe, North America, and Australasia
}

\author{
Y. de Haas, ${ }^{* 1}$ J. E. Pryce,†‡ M. P. L. Calus, ${ }^{*}$ E. Wall,§ D. P. Berry,\# P. Løvendahl,II N. Krattenmacher,ף \\ F. Miglior, ${ }^{* *} † \dagger$ K. Weigel, ‡† D. Spurlock,§§ K. A. Macdonald,\#\# B. Hulsegge, ${ }^{*}$ and R. F. Veerkamp* \\ *Animal Breeding and Genomics Centre, Wageningen UR Livestock Research, P.O. Box 338, NL-6700 AH Wageningen, the Netherlands \\ †Biosciences Research Division, Department of Economic Development, Jobs, Transport and Resources and Dairy Futures Cooperative \\ Research Centre, Agribio, 5 Ring Road, Bundoora, VIC 3083, Australia \\ fLa Trobe University, Bundoora, VIC 3083, Australia \\ §Animal and Veterinary Sciences, SRUC, Easter Bush Campus, EH25 9RG, Scotland, United Kingdom \\ \#Animal \& Grassland Research and Innovation Centre, Teagasc, Moorepark, Co. Cork, Ireland \\ $\|$ Aarhus University, Dept. Molecular Biology and Genetics, QGG, 8830 Tjele, Denmark \\ TInstitute of Animal Breeding and Husbandry, Christian-Albrechts-University, Hermann-Rodewald-Straße 6, 24118 Kiel, Germany \\ ${ }^{* *}$ Canadian Dairy Network, Guelph, Ontario, N1K 1E5, Canada \\ ††CGIL, University of Guelph, Guelph, Ontario, N1G 2W1, Canada \\ $\ddagger \ddagger D$ epartment of Dairy Science, University of Wisconsin, Madison 53706 \\ $\S \S$ Department of Animal Science, lowa State University Ames 50011 \\ \#\#DairyNZ, Private Bag 3221, Hamilton 3240, New Zealand
}

\begin{abstract}
With the aim of increasing the accuracy of genomic estimated breeding values for dry matter intake (DMI) in Holstein-Friesian dairy cattle, data from 10 research herds in Europe, North America, and Australasia were combined. The DMI records were available on 10,701 parity 1 to 5 records from 6,953 cows, as well as on 1,784 growing heifers. Predicted DMI at $70 \mathrm{~d}$ in milk was used as the phenotype for the lactating animals, and the average DMI measured during a 60- to 70-d test period at approximately $200 \mathrm{~d}$ of age was used as the phenotype for the growing heifers. After editing, there were 583,375 genetic markers obtained from either actual high-density single nucleotide polymorphism (SNP) genotypes or imputed from 54,001 marker SNP genotypes. Genetic correlations between the populations were estimated using genomic REML. The accuracy of genomic prediction was evaluated for the following scenarios: (1) within-country only, by fixing the correlations among populations to zero, (2) using near-unity correlations among populations and assuming the same trait in each population, and (3) a sharing data scenario using estimated genetic correlations among populations. For these 3 scenarios, the data set was divided into 10 sub-populations stratified by progeny group of sires; 9 of these sub-populations were used (in turn) for the genomic prediction and the
\end{abstract}

Received December 18, 2014.

Accepted June 2, 2015.

${ }^{1}$ Corresponding author: Yvette.deHaas@wur.nl tenth was used for calculation of the accuracy (correlation adjusted for heritability). A fourth scenario to quantify the benefit for countries that do not record DMI was investigated (i.e., having an entire country as the validation population and excluding this country in the development of the genomic predictions). The optimal scenario, which was sharing data, resulted in a mean prediction accuracy of 0.44 , ranging from 0.37 (Denmark) to 0.54 (the Netherlands). Assuming nearunity among-country genetic correlations, the mean accuracy of prediction dropped to 0.40 , and the mean within-country accuracy was 0.30 . If no records were available in a country, the accuracy based on the other populations ranged from 0.23 to 0.53 for the milking cows, but were only 0.03 and 0.19 for Australian and New Zealand heifers, respectively; the overall mean prediction accuracy was 0.37 . Therefore, there is a benefit in collaboration, because phenotypic information for DMI from other countries can be used to augment the accuracy of genomic evaluations of individual countries. Key words: dry matter intake, genomic prediction, validation, multi-trait genomic REML, international collaboration

\section{INTRODUCTION}

Feed cost is the single largest expense in dairy production (European Commission: Agriculture and Rural Development, 2011; Vallimont et al., 2011) and has increased substantially in recent years (Garcia, 2009). Although feed efficiency is an important contributor to profitability in the dairy industry, little attention 
has so far been given to improving it through direct genetic selection (Linn, 2006; Zamani et al., 2008) despite the known existence of heritable genetic variation (Berry and Crowley, 2013). Feed efficiency has improved through selection for milk production; however, selection for milk production alone leads to genetically inferior reproductive performance (Veerkamp and Beerda, 2007; Berry and Crowley, 2013) partly due to greater negative energy balance (Veerkamp et al., 2001) because the amount of feed required does not match the increase in actual feed intake. The lack of direct inclusion of feed intake in dairy cow breeding goals is mainly due to the difficulty and costs associated with acquiring individual animal feed intake measurements (Veerkamp, 1998).

For such difficult and costly-to-measure traits, there is growing interest in combining data from international research populations for genetic analysis (Banos et al., 2012; de Haas et al., 2012; Veerkamp et al., 2012; Berry et al., 2014). The justification for combining genotypes and phenotypes from different research organizations includes greater statistical power for genome-wide association studies as well as improved accuracy of genetic or genomic predictions.

The existence of genotype by environment $(\mathbf{G} \times \mathbf{E})$ interactions between populations poses a challenge in the optimal exploitation of phenotypic information from alternative sources; such $\mathrm{G} \times \mathrm{E}$ may also include differences in trait definitions between populations. A multi-trait model can, however, consider traits measured in different environments as separate traits, and therefore accommodate $\mathrm{G} \times \mathrm{E}$ interactions. A multitrait model can also accommodate records taken at different stages of life; Macdonald et al. (2014) reported that residual feed intake (i.e., DM corrected for growth, maintenance, and lactation requirements) is correlated in lactating cows and growing heifers. Genomic predictions for multiple traits are straightforward if genomic REML (G-REML) methodology is used (de Haas et al., 2012).

The objective of the present study was to estimate the accuracy of genomic prediction for DMI, when analyzed in a multi-trait framework, using the largest existing international database (gDMI) of individual dairy animal DMI observations from Europe, North America, and Australasia (Berry et al., 2014) and their associated genotypes (Pryce et al., 2014). Of particular interest was the suitability of combining DMI data generated under experimental conditions to predict genetic merit for DMI but also the ability to predict genetic merit for cow DMI in a population where no cow DMI phenotypic information existed or that only had phenotypic information on growing heifers.

\section{MATERIALS AND METHODS}

\section{Data Collection}

Data on individual daily DMI of Holstein-Friesian cows and heifers were available from 10 populations in Europe, North America, and Australasia. Populations included Australia (AUS), Canada (CAN), Denmark (DNK), Germany (GER), Ireland (IRL), the Netherlands (NLD), New Zealand (NZL), United Kingdom (UK), and Iowa and Wisconsin in United States of America (US_I and US_W, respectively). Only cow data from parities 1 to 5 were retained for inclusion in the analysis in addition to feed intake data on growing heifers ( $<2$ yr of age) from Australia and New Zealand. Furthermore, 100 of the Australian growing heifers also had DMI recorded during the first lactation. A more detailed description of the merging of the data and variance components across the different populations is given by Berry et al. (2014). In total, 224,174 weekly animal feed intake records from 10,701 parities on 6,953 cows were available, as well as 1,784 records on nulliparous animals. The production systems represent a diversity of rations fed within and across countries.

\section{Phenotype}

Dry matter intake was predicted for each animal across the 5 parities standardized at DIM 70, and used as the trait for the genomic prediction analysis. Following Berry et al. (2014), DMI at 70 DIM was chosen as the phenotype because this is the period when the largest number of actual DMI observations existed within the complete data set and, at this mid-point of the data trajectory, most benefit is taken from the records at other DIM or lactations to estimate the cow effects.

Predicted DMI of animals was obtained from a fitted random regression model in ASReml (Gilmour et al., 2009 ) through 224,174 weekly DMI records as described in detail by Berry et al. (2014). The DMI observations were corrected for the fixed effects of the interaction between parity and DIM (sixth-order polynomial), herd-year-season class, experimental treatment related to each weekly record, and a specific DIM curve for each herd by parity (1 to 5 ) was fitted as a third-order polynomial. As random effect, third-order polynomial was fitted for each animal for each of the 5 parties. Lactation stage was defined as $\leq 30$ DIM, 31 to 100 DIM, 101 to 200 DIM, and >200 DIM and heterogeneous residual variances were assumed within stage by parity $(1,2,3,4,5+) ; 7$ classes had fewer than 10 records and were therefore merged to an adjacent lactation stage class within the same parity and population. The re- 
sidual variance varied across these 184 classes, ranging from 0.59 to $19.0 \mathrm{~kg}^{2}$, and averaged $5.5 \mathrm{~kg}^{2}$.

Using this approach, ASReml used all records in the first 5 parities together with simultaneously estimated permanent environmental covariances within and across parities to predict, for all 6,953 cows, the cow effect as the average DMI at 70 DIM across the 5 parities. The prediction error was used to calculate the accuracy of prediction for each animal as accuracy $=\sqrt{1-\left(\frac{S E^{2}}{\sigma^{2}}\right)}$, where SE is the prediction error for the BLUP provided by ASReml, and $\sigma^{2}$ the estimated variance for the cow effects (or the SE for an animal without records), which was $3.0 \mathrm{~kg}^{2}$. Some animals had records in later parity only or had too few records to predict DMI at 70 DIM accurately (Figure 1). Ideally, records should be deregressed to a common variance and appropriately weighted in the subsequent analysis. However, difference in prediction accuracy was ignored in further analysis, apart from discarding 202 animals with DMI prediction accuracy of $<0.43$.

Feed intake in the growing heifers represented the average daily feed intake of a 60- to 70-d test period when the heifers were approximately $200 \mathrm{~d}$ old (Williams et al., 2011). Average DMI were available on 843 AUS and 941 NZL growing heifers, and these were pre-adjusted for age, batch, and breed of the sire.

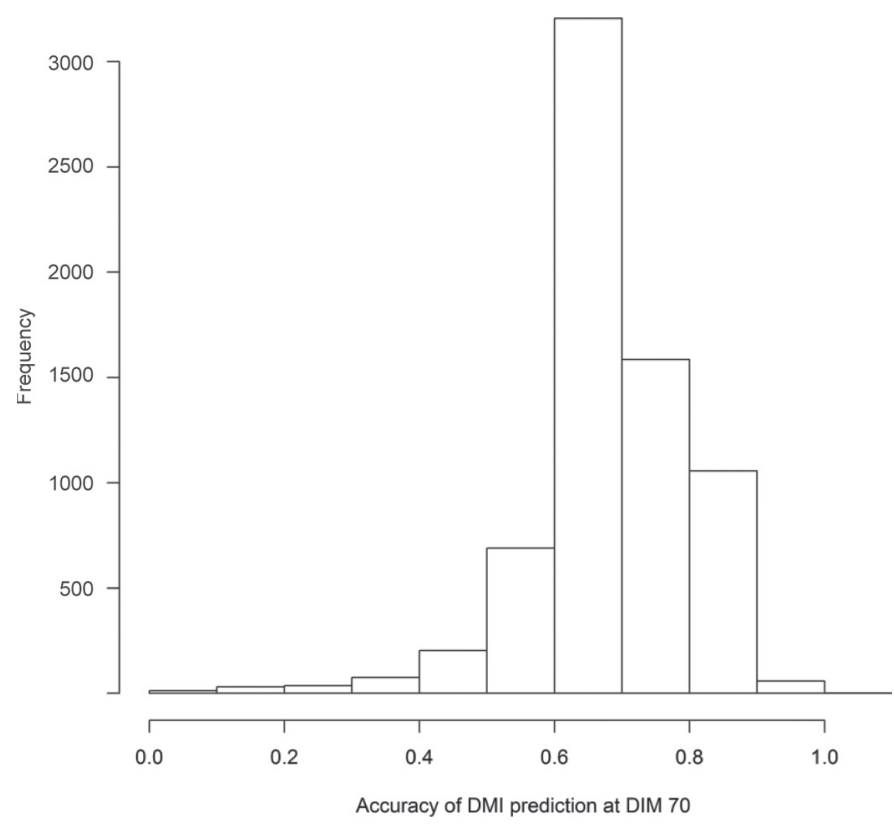

Figure 1. Distribution of the prediction accuracy of DMI at 70 DIM for each cow.

\section{Generation of Relationship Matrix}

Single nucleotide polymorphism genotypes were available on 5,999 animals, of which 5,429 had phenotypic information in this study. A total of 1,888 animals had Illumina high-density (HD) genotype information, and 4,111 had genotype information from the Illumina Bovine50 BeadChip (Illumina Inc., San Diego, CA). Imputation of the Illumina HD genotypes for 5,999 animals to 591,213 SNP was performed using Beagle (Browning and Browning, 2009) and has been described in detail elsewhere (Pryce et al., 2014). The North American and UK genotypes were imputed to HD in one batch, and the European and Australasian genotypes were imputed to HD in another batch. This was because of sensitivities surrounding genotype ownership. The UK genotypes were imputed in both data sets enabling us to examine the quality of imputation. The same genotype editing rules were applied to both data sets, as follows: (1) call rates (across animals) of individual SNP $\geq 95 \%$; (2) overall call rates (across SNP) for each animal $\geq 95 \%$; (3) excluding mitochondrial SNP, Y SNP, unmapped and mismapped SNP; (4) removing SNP deviating from Hardy-Weinberg equilibrium. In preparing the genotypes, no edits were made on minor allele frequency (MAF), as it was possible that SNP with low MAF in one batch may be have higher MAF in another batch. The correlation between allele frequencies of genotypes imputed to HD between batches was high. For the UK animals that were imputed as part of batches 1 and 2, the proportion of genotypes that differed was $2.2 \%$, which is an assessment of imputation accuracy. It was confirmed that very few $(0.025 \%)$ were because of switching homozygotes. In total, 591,213 SNP remained after the genotype preparation process.

In the subset of genotyped animals with phenotypes used in this study, nonsegregating SNP as well as SNP for which not all $3 \mathrm{SNP}$ were present were removed, leaving 583,375 SNP for the calculation of the genomic relationship matrix using the first method described in VanRaden (2008). Allele frequencies required for this procedure were computed across all genotyped animals included in the analysis. Pedigree information of all animals was traced back to the founder population; aliases in the pedigree were removed through the use of the Interbull identification cross reference tables and manual curation of the pedigree. The total pedigree file consisted of 271,545 records.

The inverse of the combined pedigree and genomic relationship matrix $\left(\mathbf{H}^{-1}\right)$ was generated as described by Berry et al. (2014) for this data set based on the procedures outlined in Aguilar et al. (2010) and Christensen and Lund (2010); that is, 


$$
\mathbf{H}^{-1}=\mathbf{A}^{-1}+\left[\begin{array}{cc}
\mathbf{0} & \mathbf{0} \\
\mathbf{0} & \left(\tilde{\mathbf{G}}^{-1}-\mathbf{A}_{22}^{-1}\right)
\end{array}\right],
$$

where $\tilde{\mathbf{G}}$ is computed as $\tilde{\mathbf{G}}=0.9 \mathbf{G}+0.1 \mathbf{A}_{22}$. The $\mathbf{H}^{-1}$ matrix represents the combined pedigree and genomic relationship between 51,486 animals, and $\mathbf{A}_{22}$ represents pedigree relationship matrix for all genotyped animals.

\section{Variance Components}

Fifty-five bivariate analyses were undertaken to estimate the genetic and residual (co)variances for predicted DMI at 70 DIM (and average DMI for the growing heifers) within and between countries, using ASReml. Default ASReml uses the average information (AI)-REML algorithms; however, when correlations are very close to unity, the expectation maximization (EM)-REML algorithm will always automatically be used to avoid boundary problems. Strictly speaking, the residual variance was an underestimate of the true residual variances because records for the cow effect were used rather than the true data. However, little impact is expected on the estimated genetic correlations and the subsequent genomic predictions, although heritability will be overestimated. A linear mixed model in ASReml (Gilmour et al., 2009), using the combined pedigree and genomic relationship matrix $\left(\mathbf{H}^{-1}\right)$, was used with the following model:

$$
\mathrm{Y}_{i j}=\mu_{j}+\operatorname{animal}_{i j}+e_{i j},
$$

where $\mu_{j}$ was the overall mean for DMI in population $j$, $\mathrm{Y}_{i j}$ was the predicted value for DMI for animal $i$ at 70 DIM or the average DMI during the recording period for the growing heifers, and $j$ represents either the trait which included DMI at 70 DIM in 9 populations (AUS, CAN, DNK, GER, IRL, US_I, NLD, UK, and US_W) or mean DMI in growing heifers in AUS and NZL. No fixed effects were included in the model because the phenotypes were already precorrected at source. Finally, animal was fitted as a random additive genetic effect, distributed following $N\left(0, \mathbf{H} \sigma_{g}^{2}\right)$, where $\mathbf{H}$ is the relationship matrix based on the combined pedigree and genomic relationship matrix, and $e$ was the residual term. A residual covariance was only considered for the bivariate analysis that included DMI for lactating animals in AUS and growing heifers in AUS.

\section{Matrix Bending}

All 55 pairwise bivariate genetic correlations were averaged into a single matrix and the resulting ma- trix was bended to be positive definite. Bending was achieved using an iterative process, to avoid unnecessary back regression of the strong correlations that were estimated with greater accuracy. In this iterative approach, the full matrix was made positive definite by replacing the negative eigenvalue to slightly positive ones in vector $\mathbf{E}$, and obtaining the new matrix by taking the correlations of the covariance matrix $\mathbf{X ~} \mathbf{E ~ X}$, where $\mathbf{X}$ is the matrix with eigenvectors for the original matrix. In the first step, only the correlations between the populations with the largest standard error of the estimated heritability were changed from the original estimated correlation to the bended correlation. This process of replacing only a subset of the correlations with the bended correlations was repeated until the most negative eigenvalue no longer approached zero. Using the same approach, the genetic correlations between populations with largest and intermediate SE for the heritability were repeatedly replaced by the bended correlations (second step), until the most negative eigenvalue no longer approached zero. Finally, all genetic correlations between all populations were replaced after the final bending step to make the full matrix positive definite.

\section{Genomic Predictions}

Genomic predictions were performed using MixBlup (http://www.mixblup.eu/), which solves the equations using preconditioned conjugate gradient (Lidauer et al., 1999). The full 11-trait model using the dense $\mathbf{H}$ matrix was not computationally feasible in ASReml, but in MixBlup a typical analysis took only $12 \mathrm{~min}$. The bended (co)variance matrix was used in the BLUP analysis, as well as the estimated residual variances, and only the mean and the additive genetic effects were fitted in the model. This scenario, called the "sharing data" scenario, used the estimated co-variances between populations and is the most promising approach when sharing data across populations in genomic prediction because it accounts for $\mathrm{G} \times \mathrm{E}$. However, 2 additional scenarios were also evaluated: (1) within-country evaluation, and (2) assuming that the trait definition in the entire population was the same and thus they were considered as the same trait in each population. For the within-country scenario, genetic correlations between DMI in all populations were set to zero. Such an approach is identical to performing a series of withincountry univariate analyses. The second scenario ("the same trait") assumed a genetic correlation close to unity (0.95) between all populations. Such an approach assumes little or no reranking due to $\mathrm{G} \times \mathrm{E}$ and is more commonly used when data are combined in reference populations. 


\section{Accuracies of Genomic Predictions}

For validation of the 3 scenarios described, the data set was divided into 10 sub-populations stratified by sire families; that is, paternal half-sibs were always in the same subpopulation. Unique animals from each country were represented in the 10 sub-populations (Table 1 ). The phenotypes of animals in 9 of the 10 groups were used in genomic predictions, and the predicted genomic breeding values for DMI for the remaining group were retained for validation. This was iterated 10 times until each of the 10 groups was used as the validation population. Because very few sires are in common between the populations, the accuracy of across-population prediction has to originate from the genomic relationships rather than the pedigree relationships. Therefore, a fourth validation scenario excluded all nongenotyped animals from the original validation subpopulations shown in Table 1.

As a fifth validation scenario, phenotypic information from an entire population (i.e., country) was not included in the reference population but used as a single validation set. Thus, the prediction accuracy was only based on information originating from the other populations (i.e., "no recording scenario"). Such a scenario could simulate a real-life situation where DMI records were not broadly available in a population, as could be the case in a real-life commercial population with a given covariance structure with the DMI phenotypes originating only from the research population.

For each validation set that was removed from the data set (in all 5 scenarios), the genomic breeding values (GEBV) obtained through the remaining data in the reference population were then correlated with a vector of phenotypes (phen) of DMI, adjusted for the fixed effects as described above. This provided the term $\mathrm{r}$ (GEBV,phen). The accuracy of true breeding values was approximated as $\mathrm{r}(\mathrm{GEBV}$, phen $) / \mathrm{h}$, where $\mathrm{h}$ was the square root of the estimated population-specific heritability for DMI estimated from the bivariate analyses with the $\mathbf{H}^{-1}$ matrix (Table 2).

These accuracies were then averaged across validation sets within each population and the standard error of the average accuracy was calculated as the standard deviation over the replicates divided by the square root of the number of replicates (10 for scenarios 1 to 4 and 11 for the fifth scenario). Similarly, the slope and intercept of the regression of phenotypes on GEBV were calculated. Mean square errors (MSE) were calculated for the "sharing data scenario" as the difference between the phenotype and the estimated breeding value adjusted for the means and averaged across validation sets. For the "no recording scenario" the intercept, slope, and MSE were calculated as well, but then first the animals were deleted that had zero breeding values, as these animals had no connection with animals in the other populations through the $\mathbf{H}$ matrix (i.e., 8 Dutch cows, 9 German cows, 81 Irish cows, and 6 Wisconsin cows).

\section{RESULTS}

\section{Descriptive Statistics}

On average, the DMI of all phenotyped lactating animals was almost $20 \mathrm{~kg} / \mathrm{d}$, with a range between 15 $\mathrm{kg} / \mathrm{d}$ (Australia) and $25 \mathrm{~kg} / \mathrm{d}$ (Wisconsin; Table 3). The coancestry between the animals in the different populations based on pedigree and as used in the $\mathbf{H}$ matrix combining genomic and pedigree information is given in Figure 2. Based on pedigree relationships, the Canadian animals were most closely related to

Table 1. Number of cows per validation set of each population in the gDMI data set [lactating cows in Australia (AUS), Canada (CAN), Denmark (DNK), Germany (GER), Iowa United States (US_I), Ireland (IRL), the Netherlands (NLD), United Kingdom (UK), Wisconsin United States (US_W), and growing heifers in Australia (AUS_h) and New Zealand (NZ_h)]

\begin{tabular}{|c|c|c|c|c|c|c|c|c|c|c|c|}
\hline \multirow[b]{2}{*}{ Population } & \multicolumn{10}{|c|}{ Validation set } & \multirow[b]{2}{*}{ Total } \\
\hline & 1 & 2 & 3 & 4 & 5 & 6 & 7 & 8 & 9 & 10 & \\
\hline AUS & 10 & 9 & 11 & 8 & 10 & 12 & 15 & 11 & 7 & 10 & 103 \\
\hline $\mathrm{CAN}$ & 20 & 12 & 23 & 16 & 22 & 27 & 27 & 23 & 15 & 17 & 202 \\
\hline DNK & 36 & 34 & 34 & 53 & 34 & 34 & 32 & 40 & 31 & 35 & 363 \\
\hline AUS_h & 60 & 73 & 73 & 83 & 67 & 75 & 71 & 73 & 79 & 88 & 742 \\
\hline NZ_h & 100 & 86 & 81 & 107 & 91 & 101 & 88 & 95 & 98 & 94 & 941 \\
\hline GER & 98 & 118 & 118 & 103 & 106 & 124 & 108 & 105 & 104 & 111 & 1,095 \\
\hline US_I & 46 & 44 & 43 & 39 & 43 & 34 & 42 & 38 & 36 & 33 & 398 \\
\hline IRL & 86 & 91 & 76 & 75 & 80 & 63 & 99 & 91 & 85 & 81 & 827 \\
\hline NLD & 228 & 242 & 241 & 215 & 232 & 217 & 207 & 218 & 205 & 236 & 2,241 \\
\hline UK & 107 & 142 & 131 & 115 & 130 & 139 & 135 & 121 & 132 & 125 & 1,277 \\
\hline US_W & 45 & 40 & 39 & 46 & 53 & 44 & 46 & 45 & 42 & 47 & 447 \\
\hline Total & 836 & 891 & 870 & 860 & 868 & 870 & 870 & 860 & 834 & 877 & 8,636 \\
\hline
\end{tabular}


Table 2. Genetic parameters (heritabilities and genetic correlations; below diagonal bivariate estimates and above diagonal bended correlations) for the predicted value for DMI at 70 DIM of lactating cows in Australia (AUS), Canada (CAN), Denmark (DNK), Germany (GER), Iowa United States (US_I), Ireland (IRL), the Netherlands (NLD), United Kingdom (UK), Wisconsin United States (US_W), and of growing heifers in Australia (AU_h) and New Zealand (NZ_h) estimated with a combined pedigree and genomic relationship matrix (respective SE in parentheses)

\begin{tabular}{|c|c|c|c|c|c|c|c|c|c|c|c|c|}
\hline $\begin{array}{l}\text { Country/ } \\
\text { population }\end{array}$ & Heritabilities & \multicolumn{11}{|c|}{ Genetic correlation } \\
\hline AUS & $\begin{array}{c}0.99^{1} \\
(0.0)\end{array}$ & & 0.66 & 0.56 & 0.27 & -0.26 & 0.32 & 0.36 & 0.00 & 0.83 & 0.57 & 0.53 \\
\hline CAN & $\begin{array}{c}0.21 \\
(0.15)\end{array}$ & $\begin{array}{c}0.83 \\
(0.75)\end{array}$ & & 0.32 & 0.30 & 0.09 & 0.13 & 0.14 & 0.04 & 0.77 & 0.80 & 0.52 \\
\hline DNK & $\begin{array}{c}0.46 \\
(0.13)\end{array}$ & $\begin{array}{c}0.71 \\
(0.63)\end{array}$ & $\begin{array}{c}-0.61 \\
(1.06)\end{array}$ & & 0.05 & -0.19 & 0.85 & 0.79 & 0.16 & 0.82 & 0.37 & 0.75 \\
\hline NZ_h & $\begin{array}{c}0.24 \\
(0.07)\end{array}$ & $\begin{array}{c}-0.90 \\
(0.54)\end{array}$ & $\begin{array}{c}-0.46 \\
(1.10)\end{array}$ & $\begin{array}{c}-0.92 \\
(0.72)\end{array}$ & $\begin{array}{c}0.07 \\
(0.40)\end{array}$ & & 0.17 & -0.06 & 0.56 & -0.14 & 0.40 & 0.15 \\
\hline GER & $\begin{array}{c}0.17 \\
(0.06)\end{array}$ & $\begin{array}{c}0.34 \\
(0.42)\end{array}$ & $\begin{array}{c}0.12 \\
(0.67)\end{array}$ & $\begin{array}{c}0.94 \\
(0.51)\end{array}$ & $\begin{array}{c}0.18 \\
(0.31)\end{array}$ & $\begin{array}{c}0.18 \\
(0.52)\end{array}$ & & 0.68 & 0.45 & 0.62 & 0.46 & 0.86 \\
\hline US_I & $\begin{array}{c}0.53 \\
(0.11)\end{array}$ & $\begin{array}{c}0.33 \\
(0.43)\end{array}$ & $\begin{array}{c}0.40 \\
(0.67)\end{array}$ & $\begin{array}{c}0.36 \\
(0.47)\end{array}$ & $\begin{array}{c}0.29 \\
(0.29)\end{array}$ & $\begin{array}{c}0.26 \\
(0.44)\end{array}$ & $\begin{array}{c}0.73 \\
(0.32)\end{array}$ & & -0.15 & 0.63 & 0.08 & 0.50 \\
\hline US_W & $\begin{array}{c}0.12 \\
(0.12)\end{array}$ & $\begin{array}{c}0.79 \\
(1.05)\end{array}$ & $\begin{array}{c}-0.64 \\
(1.42)\end{array}$ & $\begin{array}{c}0.79 \\
(0.76)\end{array}$ & $\begin{array}{l}0.81 \\
(0.76)\end{array}$ & $\begin{array}{c}-0.40 \\
(1.23)\end{array}$ & $\begin{array}{c}0.99 \\
(0.80)\end{array}$ & $\begin{array}{c}0.65 \\
(0.69)\end{array}$ & $\begin{array}{c}0.98 \\
(1.41)\end{array}$ & $\begin{array}{c}0.99 \\
(0.81)\end{array}$ & $\begin{array}{c}0.87 \\
(0.92)\end{array}$ & \\
\hline
\end{tabular}

${ }^{1}$ Converted at the boundary of parameters space due to few records and 2 sets of extreme animals.

each other (mean coancestry of 0.16) followed by US_I (0.14) and DNK (0.09). Although most of the countries had a mean coancestry of between 0.02 and 0.04 with all other countries, AUS_h (0.01) and NZ_h (0.00) had very low mean pedigree coancestry with the other countries and Canada had a stronger mean coancestry $(0.06)$ with the other countries. This average coancestry pattern follows very closely the previous findings by Van Doormaal et al. (2005). Using Interbull production and pedigree data, Canadian bulls had the highest percentage of nonlocal daughters (55\%), followed by US bulls (50\%), whereas Australia and New Zealand bulls had only $1 \%$ of nonlocal daughters. Based on the $\mathbf{H}$ matrix, the animals in NZL were more closely related to each other than when the relationships were estimated using pedigree only.

\section{Genetic Parameters}

The estimated within-population heritability estimates for predicted DMI at 70 DIM ranged from 0.12 to 0.53 (Table 2). Strong genetic correlations existed among some populations (>0.8; e.g., between Denmark and Germany and between Denmark and the Netherlands; Table 2); weak and even negative genetic correlations were evident among some other populations.
Nonetheless, the standard errors of some correlations were large, which may have been attributable to fewer DMI records for those countries and poor connectedness between countries. The genetic correlations among populations with relatively large number of records in lactating cows (GER, IRL, NLD, and UK) ranged between 0.48 and 0.76 , with only the correlation between IRL and NLD being weak (0.02).

The large SE of the genetic correlation forced severe bending to make the genetic co-variance matrix positive definite. Still, the bended genetic correlations deviated less than $2 \mathrm{SE}$ from the estimated genetic correlations (Table 2).

\section{Accuracy of Genomic Predictions}

Mean accuracy of genomic prediction was 0.37 and ranged across countries from 0.17 to 0.51 when a within country evaluation was performed (i.e., assuming a zero genetic correlation). The accuracy of the genomic prediction was greater for those populations with more DMI phenotypic observations (Table 4). Considerable variation in the accuracy of the genomic prediction existed for the countries with fewer DMI phenotypic observations, probably reflecting the closeness of relationships between the recorded animals within that 
Table 3. Number of lactations and animals with phenotypic information available per population, and the mean parity, DIM, and DMI per population with the corresponding SD for DMI

\begin{tabular}{|c|c|c|c|c|c|c|}
\hline \multirow[b]{2}{*}{$\begin{array}{l}\text { Country/ } \\
\text { population }\end{array}$} & \multirow[b]{2}{*}{$\begin{array}{c}\text { Lactations, } \\
\text { no. }\end{array}$} & \multirow[b]{2}{*}{$\begin{array}{c}\text { Cows, } \\
\text { no. }\end{array}$} & \multirow[b]{2}{*}{$\begin{array}{l}\text { Mean } \\
\text { parity }\end{array}$} & \multirow{2}{*}{$\begin{array}{l}\text { Mean } \\
\text { DIM }\end{array}$} & \multicolumn{2}{|c|}{ DMI, $\mathrm{kg}$ of DM/d } \\
\hline & & & & & Mean & $\mathrm{SD}$ \\
\hline \multicolumn{7}{|l|}{ Cows } \\
\hline Canada & 411 & 202 & 1.6 & 138 & 21.2 & 4.4 \\
\hline Denmark & 668 & 363 & 1.7 & 138 & 21.1 & 3.7 \\
\hline Germany & 1,141 & 1,095 & 1.2 & 134 & 20.3 & 4.0 \\
\hline Iowa & 398 & 398 & 1.7 & 76 & 22.3 & 4.3 \\
\hline Ireland & 1,677 & 827 & 2.1 & 139 & 16.8 & 3.4 \\
\hline Netherlands & 2,956 & 2,241 & 1.9 & 110 & 20.5 & 3.7 \\
\hline UK & 2,840 & 1,277 & 1.9 & 134 & 16.2 & 4.4 \\
\hline Wisconsin & 507 & 447 & 2.1 & 124 & 25.1 & 5.3 \\
\hline Australia & 103 & 103 & 1.0 & 145 & 17.4 & 2.4 \\
\hline Total cows & 10,701 & 6,953 & 1.8 & 126 & 19.0 & 4.8 \\
\hline \multicolumn{7}{|l|}{ Heifers } \\
\hline Australia & 843 & 843 & & & 8.3 & 1.4 \\
\hline New Zealand & 941 & 941 & & & 7.6 & 1.1 \\
\hline Total heifers & 1,784 & 1,784 & & & 7.9 & 1.3 \\
\hline All animals & 12,485 & 8,737 & & & & \\
\hline
\end{tabular}

country, and therefore between validation and reference sets. When the data of other populations was included in the genomic prediction process, through the estimated genetic correlations, the accuracy for most populations increased by up to 0.06 , whereas for 2 populations (US_W and CAN), a substantial increase in accuracy (0.18 and 0.23 for US_W and CAN, respectively) was detected. Both populations had the lowest accuracy when based only on their own data (i.e., analysis with zero genetic covariance assumed among populations).

The accuracy of genomic predictions reduced by 0.01 to 0.07 for lactating animals and by 0.06 to 0.09 for growing animals when $\mathrm{G} \times \mathrm{E}$ among populations was ignored (i.e., assuming genetic correlations of 0.95 among the populations). Hence, adding data but not taking into account the correct correlation structure may have unfavorable repercussions for the accuracy of prediction.

Compared with using all animals in the validation set, we also investigated the accuracy considering only genotyped animals in the reference set. This was expected to generate greater accuracy because there are few bulls in common between most populations, and unrelated validation animals might have weakened the correlation between validation and reference population. However, using only the genotyped animals in the validation set gave a substantially higher increase in accuracy for only IRL $(+0.16)$, DNK $(+0.06)$, AUS_h $(+0.02)$, and NZ_h $(+0.07)$ compared with scenarios where all animals were included in the validation population (Table 4).

When entire populations constituted the validation subset but were not included in the generation of ge- nomic predictions, substantial information was gained from the records in the other populations. For the populations with lactating animals, accuracy ranged from 0.23 to 0.53 but was lower for the growing populations; that is, 0.03 (AUS_h) and 0.19 (NZ_h) (Table 4). It appears that the populations with a large own data set (NLD and UK) had less benefit from other populations. This is an artifact of the validation procedure, because excluding, for example, the Dutch population gives a much larger reduction in the reference population compared with removing, for example, the smaller CAN population of data.

The regression of the phenotypes on the estimated breeding values in the "sharing data" scenario gave intercepts that were slightly negative, suggesting that the zero breeding values in each country represented a slightly lower than average DMI. The slope of the regressions was very close to unity for the "sharing data scenario," as expected when breeding values are estimated without bias (Table 5), but more variable when no data were used in the country that was predicted (POP).

\section{DISCUSSION}

We have shown that combining data across populations is useful for increasing the accuracy of genomic predictions when the data available within each country is limited. Despite the fact that across populations, DMI is recorded in different ways, at different age classes, and with few sires in common between the populations, all populations benefitted from the phenotypic observations of the other populations. In the present 


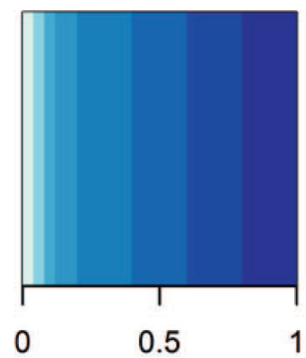

\section{Relationships between gDMI animals}
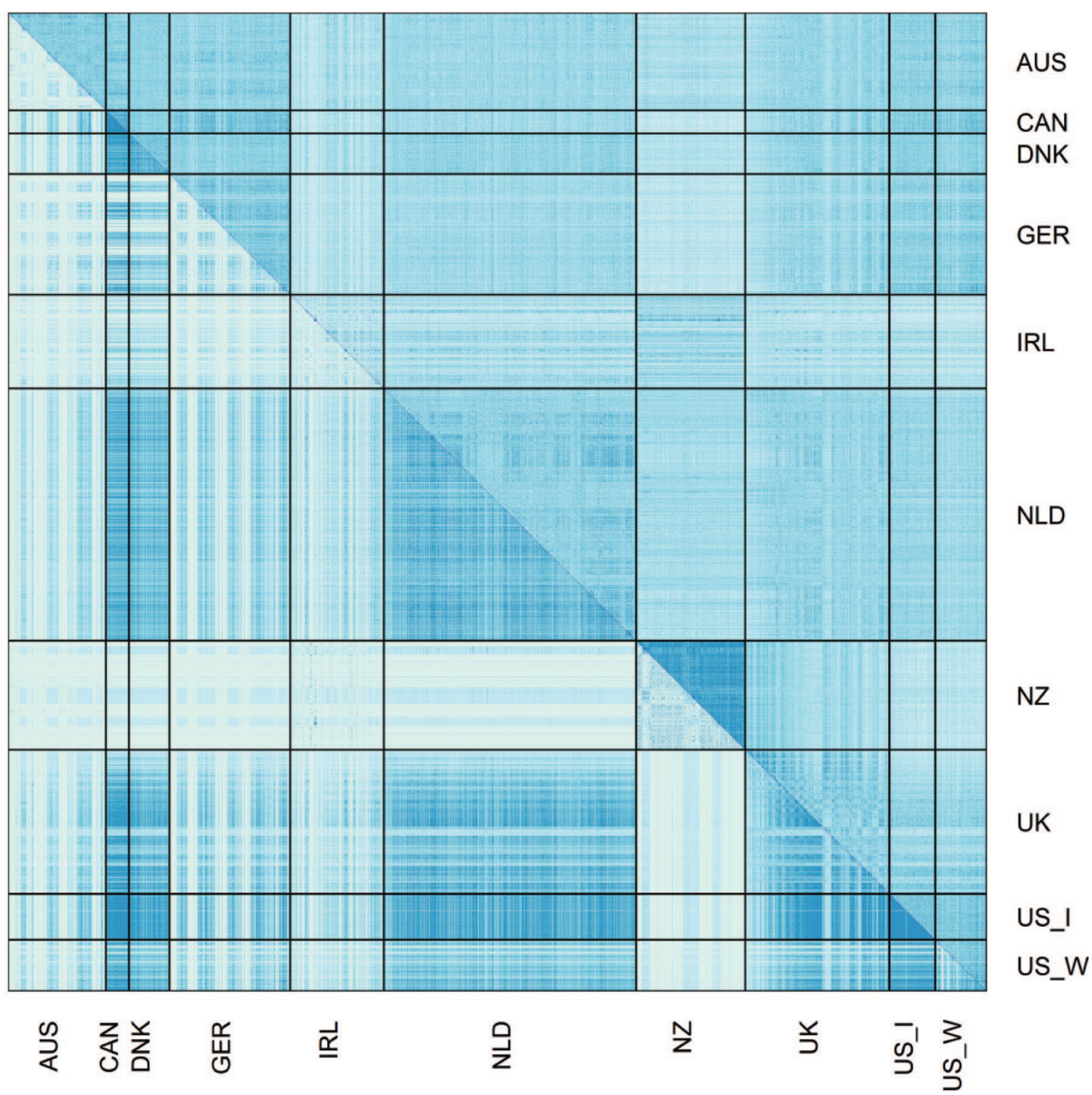

Figure 2. Heatmap showing strength of relationship between animals in the 10 populations in the gDMI data set [i.e., Australia (AUS), Canada (CAN), Denmark (DNK), Germany (GER), Iowa United States (US_I), Ireland (IRL), the Netherlands (NLD), New Zealand (NZ), United Kingdom (UK), Wisconsin United States (US_W)] estimated with a pedigree relationship matrix (below diagonal) and $\mathbf{H}$ matrix (above diagonal). Color version available online.

study, DMI at 70 DIM was chosen as the phenotype of interest because most of the available feed intake data resided close to this period of lactation but also because of the critical importance of this period in lactation. However, DMI for 70 DIM may not be genetically the same trait as DMI in other stages of lactation, although 
Table 4. The accuracy of genomic prediction estimated in a multi-trait run between all populations in the gDMI data set [lactating cows in Canada (CAN), Denmark (DNK), Germany (GER), Iowa United States (US_I), Ireland (IRL), the Netherlands (NLD), United Kingdom (UK), Wisconsin United States (US_W), and growing heifers in Australia (AU_h) and New Zealand (NZ_h)]

\begin{tabular}{|c|c|c|c|c|c|c|c|c|c|c|}
\hline Scenario $^{1}$ & $\mathrm{CAN}$ & DNK & AUS_h & NZ_h & GER & US_I & IRL & NLD & UK & US_W \\
\hline $\mathrm{Rg}$ & $\begin{array}{l}0.40 \\
(0.189)\end{array}$ & $\begin{array}{l}0.37 \\
(0.084)\end{array}$ & $\begin{array}{l}0.39 \\
(0.041)\end{array}$ & $\begin{array}{l}0.44 \\
(0.049)\end{array}$ & $\begin{array}{l}0.45 \\
(0.070)\end{array}$ & $\begin{array}{l}0.46 \\
(0.063)\end{array}$ & $\begin{array}{l}0.48 \\
(0.055)\end{array}$ & $\begin{array}{l}0.54 \\
(0.037)\end{array}$ & $\begin{array}{l}0.49 \\
(0.082)\end{array}$ & $\begin{array}{c}0.38 \\
(0.153)\end{array}$ \\
\hline $\operatorname{Rg} 1$ & $\begin{array}{c}0.33 \\
(0.196)\end{array}$ & $\begin{array}{l}0.36 \\
(0.093)\end{array}$ & $\begin{array}{l}0.30 \\
(0.043)\end{array}$ & $\begin{array}{l}0.38 \\
(0.051)\end{array}$ & $\begin{array}{l}0.43 \\
(0.065)\end{array}$ & $\begin{array}{l}0.43 \\
(0.066)\end{array}$ & $\begin{array}{l}0.44 \\
(0.070)\end{array}$ & $\begin{array}{c}0.51 \\
(0.037)\end{array}$ & $\begin{array}{l}0.48 \\
(0.079)\end{array}$ & $\begin{array}{c}0.35 \\
(0.141)\end{array}$ \\
\hline Geno & $\begin{array}{c}0.38 \\
(0.192)\end{array}$ & $\begin{array}{l}0.43 \\
(0.079)\end{array}$ & $\begin{array}{l}0.41 \\
(0.044)\end{array}$ & $\begin{array}{l}0.51 \\
(0.084)\end{array}$ & $\begin{array}{l}0.39 \\
(0.079)\end{array}$ & $\begin{array}{l}0.43 \\
(0.055)\end{array}$ & $\begin{array}{l}0.64 \\
(0.146)\end{array}$ & $\begin{array}{c}0.44 \\
(0.063)\end{array}$ & $\begin{array}{l}0.50 \\
(0.109)\end{array}$ & $\begin{array}{c}0.38 \\
(0.228)\end{array}$ \\
\hline
\end{tabular}

${ }^{1}$ Five scenarios were run: (1) within-country evaluation, where all correlations between the populations were put to zero (Rg0); (2) sharing data scenario, where estimated correlations between the populations were used $(\mathrm{Rg})$; (3) same trait scenario, where all correlations between the populations were set to 0.95 (Rg1); (4) as the Rg scenario but all nongenotyped animals were excluded from the validation sets (Geno); and (5) no recording scenario, where phenotypes from a complete population were deleted from the reference population (Pop) and using that population for validation. The corresponding SE is shown in parentheses, except for Pop, where only one replicate is available.

the genetic correlations between DMI at approximately 70 DIM and other stages of lactation are all positive (Koenen and Veerkamp, 1998; Berry et al., 2007).

Many of the within-population heritability estimates were close to each other and are consistent with previously published heritability estimates for DMI in these populations (Coffey et al., 2001; Berry et al., 2007; de Haas et al., 2012; Spurlock et al., 2012) and elsewhere (Sondergaard et al., 2002; Vallimont et al., 2011). Genetic correlations between DMI in the different populations were relatively weak, especially when compared with genetic correlations for milk yield between populations. Nonetheless, the large SE in the present study makes it difficult to compare all genetic correlations as some exhibited random variation. The genetic correlations for DMI among the populations with larger phenotypic data sets were more promising, with values between 0.48 and 0.76 (except between IRL and NLD that had a value of 0.02). Considering the differences in recording method, diet, and management among the populations, considerable strengthening in the correlations could be expected if data recording and management were standardized. Furthermore, strengthening the extent of genetic connectedness among populations with feed intake observations may also help in improving the precision of the estimated genetic correlations. The dendrogram based on the bended genetic co-variance matrix suggests that, in terms of trait definition and connectedness, there are 3 groups of populations more similar than the rest (Figure 3). The 3 groups are (1) the Australian and New Zealand heifer data plus the Irish cows; (2) the Australian lactating data, plus the Dutch, Canadian, and UK data; and (3) the data collected at both universities in the United States plus Germany and Denmark. Nevertheless, the genetic correlations estimated in the present study were not

Table 5. The intercept and slope of the regression of phenotype on estimated breeding values estimated in a multi-trait run between all populations in the gDMI data set [lactating cows in Canada (CAN), Denmark (DNK), Germany (GER), Iowa United States (US_I), Ireland (IRL), the Netherlands (NLD), United Kingdom (UK), Wisconsin United States (US_W), and growing heifers in Australia (AU_h) and New Zealand (NZ_h)] as well as the calculated mean square errors (MSE) for 2 scenarios

\begin{tabular}{|c|c|c|c|c|c|c|c|c|c|c|}
\hline Scenario $^{1}$ & CAN & DNK & AUS_h & NZ_h & GER & US_I & IRL & NLD & UK & US_W \\
\hline \multicolumn{11}{|l|}{$\mathrm{Rg}$} \\
\hline Intercept & $\begin{array}{c}-0.077 \\
(0.041)\end{array}$ & $\begin{array}{c}-0.203 \\
(0.050)\end{array}$ & $\begin{array}{c}-0.069 \\
(0.011)\end{array}$ & $\begin{array}{c}-0.041 \\
(0.011)\end{array}$ & $\begin{array}{c}-0.246 \\
(0.042)\end{array}$ & $\begin{array}{c}-0.418 \\
(0.082)\end{array}$ & $\begin{array}{c}-0.012 \\
(0.008)\end{array}$ & $\begin{array}{c}-0.328 \\
(0.027)\end{array}$ & $\begin{array}{c}-0.209 \\
(0.033)\end{array}$ & $\begin{array}{r}-0.155 \\
(0.067)\end{array}$ \\
\hline MSE & $\begin{array}{c}1.712 \\
(0.218)\end{array}$ & $\begin{array}{c}1.464 \\
(0.186)\end{array}$ & $\begin{array}{c}0.660 \\
(0.038)\end{array}$ & $\begin{array}{c}0.602 \\
(0.027)\end{array}$ & $\begin{array}{c}1.952 \\
(0.110)\end{array}$ & $\begin{array}{l}1.473 \\
(0.116)\end{array}$ & $\begin{array}{l}0.794 \\
(0.044)\end{array}$ & $\begin{array}{l}1.145 \\
(0.025)\end{array}$ & $\begin{array}{c}1.148 \\
(0.030)\end{array}$ & $\begin{array}{l}1.186 \\
(0.113)\end{array}$ \\
\hline \multicolumn{11}{|l|}{ Pop } \\
\hline MSE & 1.908 & 1.555 & 0.703 & 0.631 & 1.998 & 1.615 & 0.866 & 1.250 & 1.231 & 1.197 \\
\hline
\end{tabular}

${ }^{1}$ Sharing data scenario, where estimated correlations between the populations were used ( $\left.\mathrm{Rg}\right)$; and the no-recording scenario, where phenotypes from a complete population were deleted from the reference population (Pop) and using that population for validation. The corresponding SE is shown in parentheses, except for Pop, where only one replicate is available 
Similarity between populations based on genetic correlations for DMI

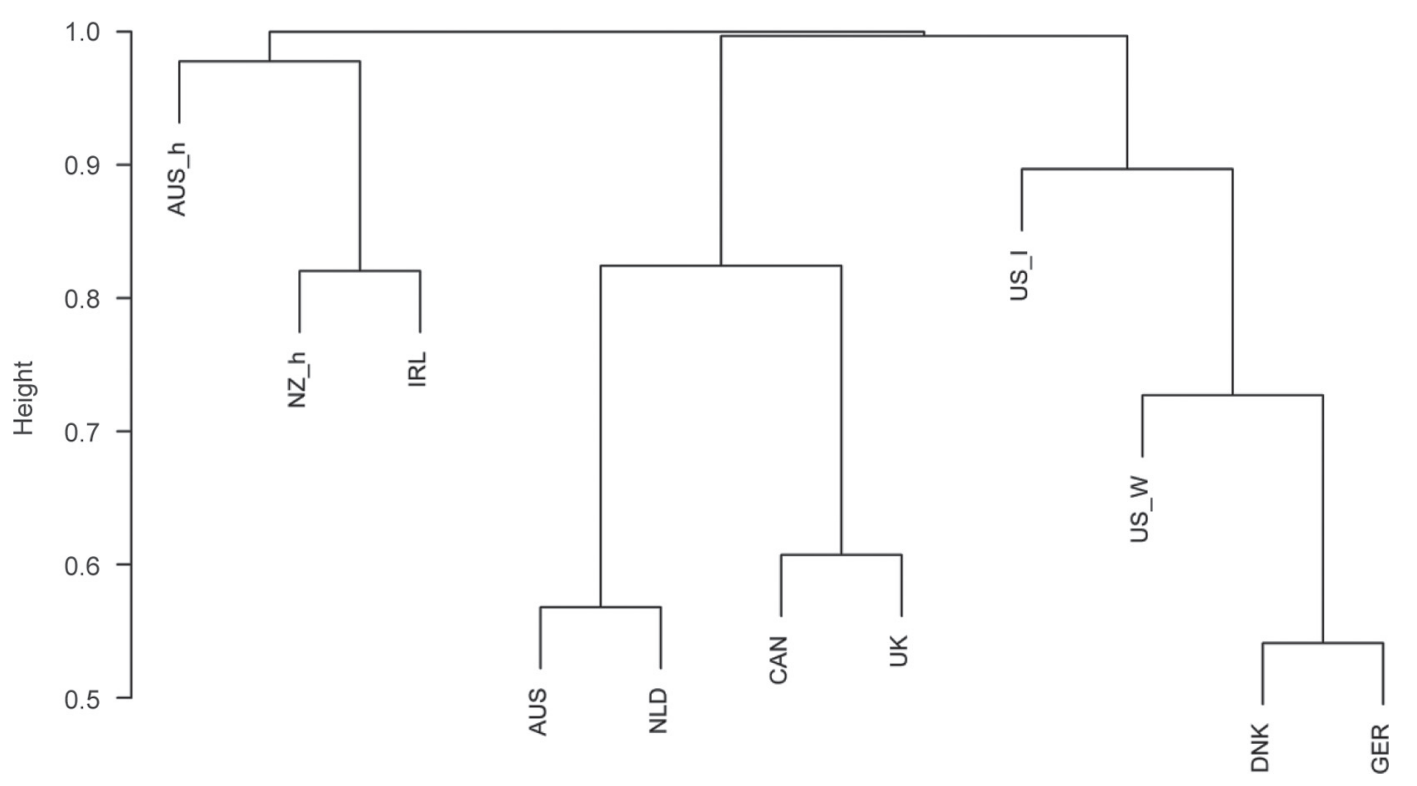

Figure 3. Dendrogram of the 11 populations of the gDMI data set [i.e., lactating cows in Australia (AUS), Canada (CAN), Denmark (DNK), Germany (GER), Iowa United States (US_I), Ireland (IRL), the Netherlands (NLD), United Kingdom (UK), Wisconsin United States (US_W), and growing heifers in Australia (AUS_h) and New Zealand (NZ_h)], showing which populations group together, based on the genetic correlation matrix for DMI.

deemed to be estimated accurately enough to suggest any regrouping of populations or to conclude that the participation of some countries in an international genomic evaluation would not be worthwhile. In fact, when no records were included in the reference population for a country the accuracy was lower (i.e., POP scenario in Table 4) and ranged from 0.23 to 0.53 , suggesting the combined data sets provided information for each country. The stronger pedigree relationships between CAN and the other populations, explains why Canada benefits most from the information of other countries (Figure 2). Moreover, given the low level of recording for DMI in most countries, there will, at least in the short term, be a benefit for each country to participate in an international genomic evaluation, as long the estimated genetic correlation structure is used and can be estimated more precisely. The validation accuracies also clearly demonstrate that it is more appropriate to use the estimated genetic correlation structure, than assume genetic correlations between countries of close to unity. Such a conclusion corroborates that of de Haas et al. (2012) using a combined data set of Australian, Dutch, and UK DMI data. The average accuracy in the study of de Haas (2012) was lower (0.35) than observed in the present study between these countries (0.47); hence, expansion of the data set (within and across countries) has proven to be useful in increasing the accuracy of selection. It should be noted, nonetheless, that the trait definition in both studies was different and therefore, caution has to be taken when comparing results.

Caution must also be taken when extrapolating the results from the present study into accuracy of young sire selection, not only because current young sires are distantly related to the animals with DMI records, but also because, by design, the reference animals in the present study are contemporaries of the validation animals, even though paternal half sibs have been combined in one set. Therefore, prediction of current young sires will have a lower accuracy. A validation method, using younger generations to quantify the accuracy, which is more common in dairy cattle evaluations (Mäntysaari et al., 2010), was not possible in the present study given the sparse DMI data in most populations. Given that we had to remove $10 \%$ of the data for validation purposes means that the accuracy obtained might be slightly lower than expected when using the full data.

For future practical applications of these findings, it is essential that the SNP regression coefficients for each population are available, because it is not practical to routinely re-run the genomic evaluation for every new animal being genotyped. One option to generate the SNP regression coefficients is to back solve the SNP ef- 
fects from the breeding values of the genotyped animals (Strandén and Garrick, 2009), which was also tested in the Netherlands using this country's own data only (Veerkamp et al., 2014).

Another requirement for breeding value estimation is to obtain greater accuracy for breeding values to become accepted in the dairy industry. One option is to expand the data and collect more feed intake records (Calus et al., 2013). This will be of benefit for all populations involved, even for larger populations. Recording DMI on new animals does not only have the advantage of providing additional records, but also provides the option to record animals more closely related to current selection candidates. Most of the data used in the present study were collected in the last 2 decades, and some of it may be too distant from the current selection candidates, in terms of genetic relationship, thereby resulting in lower accuracy of selection (Habier et al., 2013). Another option to increase accuracy of selection is to make better use of the existing DMI data in the analysis. In the present study, all DMI records of an animal were summarized in a cow effect at 70 DIM, and this trait was used in the analysis. It would be worthwhile investigating if this is an optimal approach, and whether including more parities or using the breeding value of an animal instead of the total animal effect (i.e., additive genetic plus permanent environmental effect) achieves a greater accuracy.

A final alternative is to not only rely on the genomic prediction of DMI to obtain an accurate breeding value in each population, but also to exploit knowledge on predictor traits (Veerkamp and Brotherstone, 1997; Berry and Crowley, 2013). Feed intake is determined by energy sinks, and for some of these traits, actual accurate breeding values are available already; for example, milk yield and body size through linear type traits (Veerkamp and Brotherstone, 1997; Koenen and Groen, 1998; Banos and Coffey, 2012). Veerkamp and Brotherstone (1997) predicted that when stature, chest width, body depth, angularity, and rump width were combined in one index, accuracies of selection on this index for DMI were 0.65 and for live weight were 0.84 (adjusted for condition score). When milk, fat, and protein yields were included in the index, the accuracy for DMI increased to 0.90. Hence, a substantial proportion of the genetic variation in DMI can be explained by differences in the predictor traits when we have sufficient data to estimate genetic correlations properly. Still, to select for more net efficient cows, the genomic predictions of DMI are required, because prediction of DMI based on the yield and type for selection will only account for the variation in the predictor traits; that is, cows that produce the same amount of milk but differ in size. To facilitate variation in this net efficiency to be incorporated in the breeding decision, either the genomic predictions of DMI are required to become more reliable or predictors of other parts of the feed intake complex are required. Promising options might include the use of mid-infrared spectra (MIR) to predict DMI (McParland et al., 2014) or using other sensors such as ear-attached movement sensors (Bikker et al., 2014). These predictor traits should be genetically correlated with DMI, but also explain variance in DMI over and above the variance that is already explained by yield and body size. In addition, it should be noted that real benefit of the predictor traits is obtained when those traits are measured on the animals for which EBV of DMI are predicted (Pszczola et al., 2013).

\section{CONCLUSIONS}

Through international collaboration, the world's largest collection of data for feed intake on genotyped dairy cattle has been created, comprising 8,737 animals. In this study, we demonstrated that, provided a multitrait approach is used, combining similar phenotypes across populations can increase the accuracy of genomic breeding values for important and rare traits, such as DMI. Therefore, there is a benefit of collaboration, as phenotypic information for DMI from other countries can be used to augment the accuracy of genomic evaluations of individual countries. The results presented here also provide indications on how to improve the informative value of the across-country reference population for DMI in the future.

\section{ACKNOWLEDGMENTS}

First, financial support for gDMI from CRV (Arnhem, the Netherlands), ICBF (Cork, Ireland), CONAFE (Madrid, Spain), DairyCo (Warwickshire, UK) directly to the gDMI consortium, and The Natural Science and Engineering Research Council of Canada and DairyGen Council of Canadian Dairy Network (Guelph, ON, Canada) is gratefully appreciated, as well as the EU FP7 IRSES SEQSEL (Grant no. 317697). Second, the providers of the phenotypes are gratefully acknowledged: The UK research data collection was funded by the Scottish Government. The Dutch research data collection was funded by projects paid by industry (CRV, Arnhem), the Dairy Product Board (PZ, Zoetermeer) and by the Dutch Ministry of Agriculture, with particular emphasis on the WhyDry project. The Australian Research was funded by the Gardiner Foundation, DEPI and Dairy Future's CRC (Melbourne, Australia). The New Zealand research was 
funded by New Zealand dairy farmers through Ministry of Business, Innovation and Employment (MBIE), DairyNZ Inc. and LIC. The US research is funded by the National Institute of Food and Agriculture (NIFA) Grant no. 0224899, from the United States Department of Agriculture (USDA, Washington, DC). Third, the providers of genotypes used in this study are gratefully acknowledged: DEPI and Dairy Future's CRC (Australia), University of Alberta (Canada), Aarhus University (Denmark), Christian-Albrechts-University (Germany), LIC and Dairy NZ Ltd. (New Zealand), the RobustMilk project (Irish, part of the UK, and part of Dutch genotypes), the National Institute of Food and Agriculture (NIFA; Washington, DC; Iowa State University, University of Wisconsin and part of the Netherlands and UK genotypes) and the Scottish Government (part of the UK genotypes). The SRUC HD genotypes were made available as part of the UK Ruminant Genetic Improvement Network, funded by Defra (IF0169). The genotyping of Danish animals were done as part of the project "Genomic Selection-From function to efficient utilization in cattle breeding," Grant no. 3405-10-0137. The genotyping of German animals was financially supported by the German Federal Ministry of Education and Research (project FUGATO-plus GENOTRACK, grant no. 0315134A), the KMSH (Kompetenzzentrum Milch-Schleswig-Holstein, Kiel, Germany), and the NOG Nord-Ost Genetic GmbH \& Co. KG (Verden, Germany).

\section{REFERENCES}

Aguilar, I., I. Misztal, D. L. Johnson, A. Legarra, S. Tsuruta, and T. J. Lawlor. 2010. Hot topic: A unified approach to utilize phenotypic, full pedigree, and genomic information for genetic evaluation of Holstein final score. J. Dairy Sci. 93:743-752.

Banos, G., and M. P. Coffey. 2012. Technical note: Prediction of liveweight from linear conformation traits in dairy cattle. J. Dairy Sci. 95:2170-2175.

Banos, G., M. P. Coffey, R. F. Veerkamp, D. P. Berry, and E. Wall. 2012. Merging and characterising phenotypic data on conventional and rare traits from dairy cattle experimental resources in three countries. Animal 6:1040-1048.

Berry, D. P., M. P. Coffey, J. E. Pryce, Y. de Haas, P. Lovendahl, N. Krattenmacher, J. J. Crowley, Z. Wang, D. Spurlock, K. Weigel, K. Macdonald, and R. F. Veerkamp. 2014. International genetic evaluations for feed intake in dairy cattle through the collation of data from multiple sources. J. Dairy Sci. 97:3894-3905.

Berry, D. P., and J. J. Crowley. 2013. Cell Biology Symposium: Genetics of feed efficiency in dairy and beef cattle. J. Anim. Sci. 91:1594-1613.

Berry, D. P., B. Horan, M. O'Donovan, F. Buckley, E. Kennedy, M. McEvoy, and P. Dillon. 2007. Genetics of grass dry matter intake, energy balance, and digestibility in grazing Irish dairy cows. J. Dairy Sci. 90:4835-4845.

Bikker, J. P., H. van Lear, R. Rump, J. Doorenbos, K. van Meurs, G. M. Griffioen, and J. Dijkstra. 2014. Technical note: Evaluation of an ear-attached movement sensor to record cow feeding behavior and activity. J. Dairy Sci. 97:2974-2979.
Browning, B. L., and S. R. Browning. 2009. A unified approach to genotype imputation and haplotype-phase inference for large data sets of trios and unrelated individuals. Am. J. Hum. Genet. 84:210-223.

Calus, M. P. L., Y. de Haas, M. Pszczola, and R. F. Veerkamp. 2013. Predicted accuracy of and response to genomic selection for new traits in dairy cattle. Animal 7:183-191.

Christensen, O. F., and M. S. Lund. 2010. Genomic prediction when some animals are not genotyped. Genet. Sel. Evol. 42:2.

Coffey, M. P., G. C. Emmans, and S. Brotherstone. 2001. Genetic evaluation of dairy bulls for energy balance traits using random regression. Anim. Sci. 73:29-40.

de Haas, Y., M. P. L. Calus, R. F. Veerkamp, E. Wall, M. P. Coffey, H. D. Daetwyler, B. J. Hayes, and J. E. Pryce. 2012. Improved accuracy of genomic prediction for dry matter intake of dairy cattle from combined European and Australian data sets. J. Dairy Sci. 95:6103-6112.

European Commission: Agriculture and Rural Development. 2011. Farm Economics Brief. No. 2 Production costs overview. Accessed Jul. 6, 2015. http://ec.europa.eu/agriculture/rica/pdf/ Brief201102.pdf.

Garcia, A. 2009. Dairy profitability 101: Milk quality and feed efficiency. Extension Extra. South Dakota State University, USDA. Accessed Jul. 6, 2015. http://pubstorage.sdstate.edu/AgBio_Publications/articles/ExEx4042.pdf.

Gilmour, A. R., B. R. Cullis, S. J. Welham, and R. Thompson. 2009. ASREML. Program user manual. NSW Agriculture, Orange Agricultural Institute, Orange, NSW, Australia.

Habier, D., R. L. Fernando, and D. J. Garrick. 2013. Genomic BLUP decoded: A look into the black box of genomic prediction. Genetics 194:597-607.

Koenen, E. P. C., and A. F. Groen. 1998. Genetic evaluation of body weight of lactating Holstein heifers using body measurements and conformation traits. J. Dairy Sci. 81:1709-1713.

Koenen, E. P. C., and R. F. Veerkamp. 1998. Genetic covariance functions for live weight, condition score, and dry-matter intake measured at different lactation stages of Holstein Friesian heifers. Livest. Prod. Sci. 57:67-77.

Lidauer, M., I. Stranden, E. A. Mantysaari, J. Poso, and A. Kettunen. 1999. Solving large test-day models by iteration on data and preconditioned conjugate gradient. J. Dairy Sci. 82:2788-2796.

Linn, J. 2006. Feed efficiency: Its economic impact in lactating cows. Adv. Dairy Technol. 18:19-28.

Macdonald, K. A., J. E. Pryce, R. J. Spelman, S. R. Davis, W. J. Wales, G. C. Waghorn, Y. J. Williams, L. C. Marett, and B. J. Hayes. 2014. Holstein-Friesian calves selected for divergence in residual feed intake during growth exhibited significant but reduced residual feed intake divergence in their first lactation. J. Dairy Sci. 97:1427-1435.

Mäntysaari, E., Z. Liu, and P. M. VanRaden. 2010. Interbull validation test for genomic evaluations. Interbull Bull. 41:17-22.

McParland, S., E. Lewis, E. Kennedy, S. G. Moore, B. McCarthy, M. O'Donovan, S. T. Butler, J. E. Pryce, and D. P. Berry. 2014. Midinfrared spectrometry of milk as a predictor of energy intake and efficiency in lactating dairy cows. J. Dairy Sci. 97:5863-5871.

Pryce, J. E., J. Johnston, B. J. Hayes, G. Sahana, K. A. Weigel, S. McParland, D. Spurlock, N. Krattenmacher, R. J. Spelman, E. Wall, and M. P. L. Calus. 2014. Imputation of genotypes from low density (50,000 markers) to high density (700,000 markers) of cows from research herds in Europe, North America, and Australasia using 2 reference populations. J. Dairy Sci. 97:1799-1811.

Pszczola, M., R. F. Veerkamp, Y. de Haas, E. Wall, T. Strabel, and M. P. L. Calus. 2013. Effect of predictor traits on accuracy of genomic breeding values for feed intake based on a limited cow reference population. Animal 7:1759-1768.

Sondergaard, E., M. K. Sorensen, I. L. Mao, and J. Jensen. 2002. Genetic parameters of production, feed intake, body weight, body composition, and udder health in lactating dairy cows. Livest. Prod. Sci. $77: 23-34$. 
Spurlock, D. M., J. C. M. Dekkers, R. Fernando, D. A. Koltes, and A. Wolc. 2012. Genetic parameters for energy balance, feed efficiency, and related traits in Holstein cattle. J. Dairy Sci. 95:5393-5402.

Strandén, I., and D. J. Garrick. 2009. Derivation of equivalent computing algorithms for genomic predictions and reliabilities of animal merit. J. Dairy Sci. 92:2971-2975.

Vallimont, J. E., C. D. Dechow, J. M. Daubert, M. W. Dekleva, J. W. Blum, C. M. Barlieb, W. Liu, G. A. Varga, A. J. Heinrichs, and C. R. Baumrucker. 2011. Short communication: Heritability of gross feed efficiency and associations with yield, intake, residual intake, body weight, and body condition score in 11 commercial Pennsylvania tie stalls. J. Dairy Sci. 94:2108-2113.

Van Doormaal, B., F. Miglior, G. Kistemaker, and P. Brand. 2005. Genetic diversification of the Holstein breed in Canada and internationally. Accessed Apr. 22, 2015. http://cgil.uoguelph.ca/dcbgc/ Agenda0503/DCBGC0503-Diversification.pdf.

VanRaden, P. M. 2008. Efficient methods to compute genomic predictions. J. Dairy Sci. 91:4414-4423.

Veerkamp, R. F. 1998. Selection for economic efficiency of dairy cattle using information on live weight and feed intake: A review. J. Dairy Sci. 81:1109-1119.

Veerkamp, R. F., and B. Beerda. 2007. Genetics and genomics to improve fertility in high producing dairy cows. Theriogenology 68:S266-S273.

Veerkamp, R. F., and S. Brotherstone. 1997. Genetic correlations between linear type traits, food intake, live weight and condition score in Holstein Friesian dairy cattle. Anim. Sci. 64:385-392.
Veerkamp, R. F., and M. P. L. Calus. G. De Jong, R. Van der Linde, and Y. de Haas. 2014. Breeding value for dry matter for Dutch bulls based on DGV for DMI and BV for predictors. Proc. World Conf. Genet. Appl. Anim. Prod. (WCGALP), Vancouver, Canada. Accessed Jul. 6, 2015. https://asas.org/docs/default-source/ wcgalp-proceedings-oral/115_paper_8665_manuscript_206_0. pdf? sfvrsn $=2$

Veerkamp, R. F., M. P. Coffey, D. P. Berry, Y. de Haas, E. Strandberg, H. Bovenhuis, M. P. L. Calus, and E. Wall. 2012. Genome-wide associations for feed utilisation complex in primiparous HolsteinFriesian dairy cows from experimental research herds in four European countries. Animal 6:1738-1749.

Veerkamp, R. F., E. P. C. Koenen, and G. De Jong. 2001. Genetic correlations among body condition score, yield, and fertility in first-parity cows estimated by random regression models. J. Dairy Sci. 84:2327-2335.

Williams, Y. J., J. E. Pryce, C. Grainger, W. J. Wales, N. Linden, M. Porker, and B. J. Hayes. 2011. Variation in residual feed intake in Holstein-Friesian dairy heifers in southern Australia. J. Dairy Sci. 94:4715-4725.

Zamani, P., S. R. Miraei-Ashtiani, and H. Mohammadi. 2008. Genetic parameters of residual energy intake and its correlations with other traits in Holstein dairy cattle. Turk. J. Vet. Anim. Sci. $32: 255-261$ 